\title{
Numerical Study on Reduction of Ambient NOx Concentration by a Flow-through ACF (Activated Carbon Fibers) Fences
}

\author{
Toshihiro Kitada $^{1^{*}}$, Makoto Nagano ${ }^{1}$, Takaaki Shimohara ${ }^{2}$, Masaaki Yoshikawa ${ }^{3}$ and Takao Kanzaki ${ }^{4}$ \\ ${ }^{1}$ Department of Environmental and Life Sciences, Toyohashi University of Technology, Japan \\ ${ }^{2}$ Kyushu University, Japan \\ ${ }^{3}$ Osaka Gas Co. Ltd., Japan \\ ${ }^{4}$ Department of Mechanical Engineering, Daido University, Japan
}

\section{Abstract}

A method to use fences filled inside with activated carbon fibers (ACF) is presented for reduction of high $\mathrm{NO}_{2}$ concentration in urban atmosphere without excess energy use. Polluted air mass in road space moves with natural- and car-induced- winds to contact with- and to flow through- ACF fences, and the ACF layer removes these pollutants. Two parameters determining the performance of the ACF fences in terms of NOx abatement were identified as (1) resistance coefficient of the ACF layer to air flow, and (2) chemical reactivity of ACF layer for NOx removal. By varying these two parameter values in their ranges obtained by laboratory experiments, the reduction of NOx concentration at roadside by the ACF fences was numerically evaluated under an idealized situation in which two cases were considered; one is the double-fences placed at both sides of road and the other is single fence set at downwind side of the road. The results showed that in both cases these "energy-free" equipment can decrease NOx concentration by $15 \sim 55 \%$ at roadside. Furthermore, it was indicated that in the double-fence case the ACF fence with lower permeability (larger resistance coefficient) shows higher reduction of NOx, while in the single fence case higher permeability reduces NOx more.

\section{Introduction}

In Japan $\mathrm{NO}_{2}$ and $\mathrm{NOx}$ nearby heavy traffic road can still be locally high [1] in spite of continuously strengthened car emission regulation. For example, though the environmental standard for $\mathrm{NO}_{2}$ in Japan, which is defined as that the daily average value of one-hour$\mathrm{NO}_{2}$ concentration should be lower than $60 \mathrm{ppb}$, is generally satisfied at observation sites operated by local and national governments, in Aichi Prefecture the maximum one-hour- $\mathrm{NO}_{2}$ was larger than $80 \mathrm{ppb}$ (with its largest value of $107 \mathrm{ppb}$ ) at 6 sites of total 23 roadside sites for one year from April of 2014 to March of 2015, and the maximum onehour-NOx $\left(=\mathrm{NO}+\mathrm{NO}_{2}\right)$ similarly exceeded $200 \mathrm{ppb}$ (with its largest value of $489 \mathrm{ppb}$ ) at 11 sites [1]. Therefore an appropriate method is required to reduce the local pollution without excess energy use and hence excess running-cost. To decrease high $\mathrm{NO}_{2}$ concentration at roadside with heavy trafic, mainly two methods were tested in Japan for the last 20 years; one is $\mathrm{TiO}_{2}$ coated panels set at road sides, and they were used, for example, on Route 43 in Osaka City, Japan. The panels trap NOx on their surface and oxidize $\mathrm{NO}$ and $\mathrm{NO}_{2}$ to $\mathrm{NO}_{3}-\left(\mathrm{HNO}_{3}\right)$. The other one is to use specially prepared soil layer. The method was applied, for example, on Route 43 in Nishinomiya City, Hyogo Pref., Japan. Micro-bial actibity in the soil layer scavenges NOx in the polluted air which is pumped into the soil layer after oxidation of NO to $\mathrm{NO}_{2}$ by generated ozone. Though these two methods showed some effects on reduction of high $\mathrm{NO}_{2}$ concentration, their shortcomings such as relatively low performance on decreasing ambient $\mathrm{NO}_{2}$ concentration, high running cost, etc. were also appeared [2].

This paper evaluates a new method which uses fences filled inside with activated carbon fibers (ACF) to decrease high $\mathrm{NO}_{2}$ and $\mathrm{NOx}$ concentrations in urban atmosphere without excess energy use. Activated carbon fibers (ACF) is known as highly effective material to remove pollutants from flue gas [3-5], and from ambient atmosphere $[6,7]$. The idea of this paper is to utilize ACF as material filled inside in the fences placed at road side. In this situation pollutants-rich air in road space moves with natural-and car-induced- winds so as to contact with- and flow through-the ACF fences. And the ACF layer removes NOx from the polluted air. This "energy-free" equipment for air pollution reduction is proposed, and its performance is numerically evaluated in hypothetical road and wind situation.

\section{Governing Equations}

For evaluation of the performance of ACF fences in NOx concentration abatement, a set of non-thermal flow equations and advection-diffusion equation of air pollutant were applied with a standard $\mathrm{k}-\varepsilon$ turbulence model $[8,9]$. ACF fence was treated as porous media [10-12]. The following equations were numerically solved with a control volume method using software of CFX5 [13].

Continuity equation:

$$
\frac{\partial}{\partial x_{i}}\left(K_{i j} U_{j}\right)=0
$$

Momentum equation:

$$
\begin{array}{r}
K_{j k} U_{k} \frac{\partial U_{i}}{\partial x_{j}}=-\frac{1}{\rho} \frac{\partial p}{\partial x_{i}}+\frac{\partial}{\partial x_{j}}\left(v_{t} K_{j k}\left(\frac{\partial U_{i}}{\partial x_{k}}+\frac{\partial U_{k}}{\partial x_{i}}\right)\right)+B_{i} \\
(i, j, k=1,2,3)
\end{array}
$$

"Corresponding Author: Dr. Toshihiro Kitada, Department of Environmental and Life Sciences, Toyohashi University of Technology, 1-1 Hibarigaoka, Tempakucho, Toyohashi, Aichi, 441-8580, Japan; E-mail: kitada@earth.ens.tut.ac.jp

Citation: Kitada T, Nagano M, Shimohara T, Yoshikawa M, Kanzaki T (2017) Numerical Study on Reduction of Ambient NOx Concentration by a Flow-through ACF (Activated Carbon Fibers) Fences. Int J Earth Environ Sci 2: 131. doi: https://doi.org/10.15344/2456-351X/2017/131

Copyright: ( $) 2017$ Kitada et al. This is an open-access article distributed under the terms of the Creative Commons Attribution License, which permits unrestricted use, distribution, and reproduction in any medium, provided the original author and source are credited. 
where $\mathrm{B}_{\mathrm{i}}$ is the resistance to the flow in the porous media (ACF fence):

$B_{i}=-\gamma R_{c} U_{i}$

Advection-diffusion equation of air pollutant:

$\frac{\partial}{\partial x_{i}}\left(\rho K_{j} U_{j} C-\rho \Gamma_{t} K_{j} \frac{\partial C}{\partial x_{j}}\right)=-\gamma k_{c} \rho C$

Equation for turbulent kinetic energy, $\mathrm{k}$ :

$\frac{\partial}{\partial x_{i}}\left(K_{i j} U_{j} k-\frac{\mathcal{V}_{t}}{\sigma_{k}} K_{i j} \frac{\partial k}{\partial x_{j}}\right)=\gamma P-\gamma \varepsilon$

Equation for dissipation of turbulent kinetic energy, $\varepsilon$ :

$\frac{\partial}{\partial x_{i}}\left(K_{i j} U_{j} \varepsilon-\frac{v_{t}}{\sigma_{\varepsilon}} K_{i j} \frac{\partial \varepsilon}{\partial x_{j}}\right)=\gamma C_{1} \frac{\varepsilon}{k} P-\gamma C_{2} \frac{\varepsilon^{2}}{k}$

Shear production term of turbulent kinetic energy, P in Eqs. (5) and (6):

$\mathrm{P}=v_{t}\left(\frac{\partial U_{i}}{\partial x_{j}}+\frac{\partial U_{j}}{\partial x_{i}}\right) \frac{\partial U_{i}}{\partial x_{j}}$

Eddy diffusivity:

$\Gamma_{t}=v_{t}=C_{\mu} \frac{k^{2}}{\varepsilon}$

Parameters (standard k- $\varepsilon$ model):

$C_{1}=1.44, C_{2}=1.92, \sigma_{k}=1.0, \sigma_{\varepsilon}=1.3, C_{\mu}=0.09$

The symbol $\gamma$ and $K_{i j}$ in the equations denote the volume porosity and the area porosity tensor, respectively. $K_{i j}$ accounts for directivity of the flow in the porous media (i.e., ACF layer in the fence) and was assumed as a unit tensor. The volume porosity $\gamma$ represents a ratio of the cavity volume in thecomputational grid cell volume.The true density of ACF is about $1.7 \sim 2.2 \mathrm{~g} \mathrm{~cm}^{-3}$. Since we use our standard packing density of ACF in the fence $=0.066 \mathrm{~g} \mathrm{~cm}^{-3}$, can be calculated as about $0.96(1-0.066 / 1.7)$ with the true density of $\mathrm{ACF}=1.7 \mathrm{~g} \mathrm{~cm}$ ${ }^{3}$; thus we assumed .Rc in Eq. 3 and kc in Eq. 4 are two important parameters characterizing ACF fence module, and will be discussed in chapter 3.

A similar system of equations but different resistance formulation and no chemical reaction was applied elsewhere [15].

\section{Removal rate coefficient, $k_{c}$ and resistance coefficient, $R_{c}$ \\ Removal rate coefficient $\mathbf{k}_{\mathrm{c}}$}

$\mathrm{NOx}\left(=\mathrm{NO}+\mathrm{NO}_{2}\right)$ removal by ACF can be influenced by several factors such as type of ACF, packing density of ACF, and coexistence of other gases [6]. For simplicity, we assumed the first order removal reaction based on the laboratory experimental data [6,7]. The experiments were conducted by sucking ambient polluted air through glass tube packed with ACF. The reaction rate coefficient kc can be evaluated from Eq. (11) by using $\mathrm{NOx}$ (and $\mathrm{NO}_{2}$ ) concentrations measured at inlet and outlet of the glass tube with passing time through the ACF layer of sampled air:

$-\frac{d}{d t}[N O x]=k_{C}[N O x]$

From Eq. (9), the reaction rate constant can be obtained as:

$k_{C}=-\frac{1}{t} \ln \left(\frac{[N O x]_{o}}{[N O x]_{i}}\right)$ where $\left[\mathrm{NO}_{\mathrm{x}}\right]_{\mathrm{i}}$ and $\left[\mathrm{NO}_{\mathrm{x}}\right]_{\mathrm{o}}$ denote NOx concentration at inlet and outlet of the glass tube packed with ACF, respectively, and $t$ is the time required for the NOx containing air passing through the ACF layer. By using experimental data [6,7], the rate coefficient $k_{c}$ in Eq. 4 was determined for packing density of ACF at $0.066 \mathrm{~g} \mathrm{~cm}^{-3}$ (corresponding to $\gamma=0.95)$ as:

$k_{c}$ for NOx: $1 \sim 2 \mathrm{~s}^{-1}$ and for $\mathrm{NO}_{2}: 2 \sim 3 \mathrm{~s}^{-1}$

In numerical experiments, we varied as a parameter ranging $0 \sim 3 \mathrm{~s}^{-1}$.

\section{Resistance coefficient $\mathbf{R}_{c}$}

Drag of ACF layer (assumed as a porous media) to the flow is included in Bi in Eq. (2). In this study, Bi was experimentally determined as Eq. (3). When air passes through a porous media, the media's resistance is expressed as Eq. (12) [15].

$\frac{p_{1}-p_{2}}{\rho L}=\alpha v V+\beta V^{2}$

where $\rho$ is the air density, $\mathrm{L}$ is the length of porous media, $v$ is the kinematic viscosity of air, $\mathrm{V}$ is the flow velocity averaged over the cross section of porous material, $p_{1}$ and $p_{2}$ are the pressure of the air flow after and before the porous media, respectively. The parameters of $a$ and in Eq. (12) are to be determined. Using laboratory experiments [7], we found that Eq. (12) can be rewritten so that only the first term is remained on the right hand side. Thus we obtained the following relation by comparing Eq. (3) with the simplified Eq. (12).

$\gamma \rho R_{c}=\rho \alpha v=\frac{p_{2}-p_{1}}{L V}$

Coefficient $R_{c}$ in $\mathrm{B}_{\mathrm{i}}$ (Eq. 3) was estimated by utilizing the laboratory experimental data [7] of pressure drop and flow velocity in ACF layer on the far right hand side in Eq. (13). Obtained Rc values for two types of ACF fence-module, panel type and slit-type module (Figure $1)$, were as follows:

$\gamma \rho R_{c} \equiv \bar{R}_{C} \cong 3700\left(\mathrm{~kg} \mathrm{~m}^{-3} \mathrm{~s}^{-1}\right)$ for panel type ACF fence module, and

$\gamma \rho R_{c} \equiv \bar{R}_{C} \cong 400\left(\mathrm{~kg} \mathrm{~m}^{-3} \mathrm{~s}^{-1}\right)$ for slit type ACF fence module

In the panel type module, ACF was packed in $10 \mathrm{~cm}$ thick with the density of $0.066 \mathrm{~g} \mathrm{~cm}^{-3}$, while in the slit type module, many thin panels of $0.6 \mathrm{~cm}$ thick with the same ACF packing density were placed parallel each other with a distance of $1.6 \mathrm{~cm}$ between adjacent thin panels $[7,11]$.

\section{Calculation Domain and Simulation Conditions}

\section{Calculation domain}

Two types of calculation domain were assumed: one is for double fences placed at both sides of the road as shown in Figure 2, and the other one is for single fence set only at lee side of the road. Pollutant was assumed to be discharged from the road surface as constant volume source with its height $1 \mathrm{~m}$ from the road surface; the source strength was $6.7 \times 10^{-8} \mathrm{kgm}^{-3} \mathrm{~s}^{-1}$; it should be noted that calculated concentrations can linearly change with this source strength. In the calculation, inside of each fence of $10 \mathrm{~cm}$ thick was resolved with a grid size of $\Delta \mathrm{x}=2 \mathrm{~cm}$ for main stream direction ( $\mathrm{x}$ axis).

Figure 3 shows grid system for the double-fences. Thickness of each fence was $10 \mathrm{~cm}$, and was resolved with $2 \mathrm{~cm}$ grid size for $\mathrm{x}$ direction. The grid size for $\mathrm{x}$ direction was smaller near the fences and was 
Citation: Kitada T, Nagano M, Shimohara T, Yoshikawa M, Kanzaki T (2017) Numerical Study on Reduction of Ambient NOx Concentration by a Flow-through ACF (Activated Carbon Fibers) Fences. Int J Earth Environ Sci 2: 131. doi: https://doi.org/10.15344/2456-351X/2017/131

Page 3 of 9

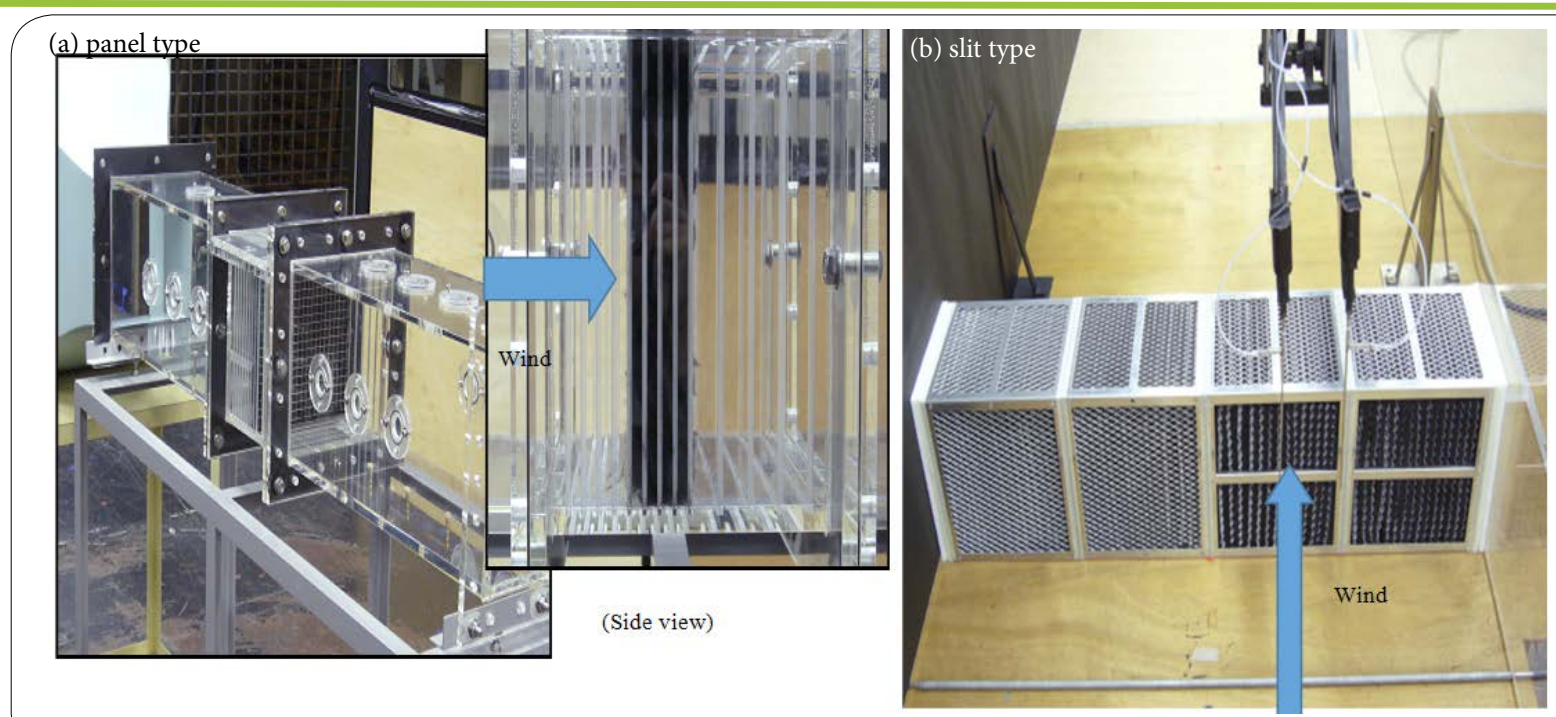

Figure 1: ACF fence modules: (a) panel type; miniature placed in laboratory, and (b) slit type; miniature.
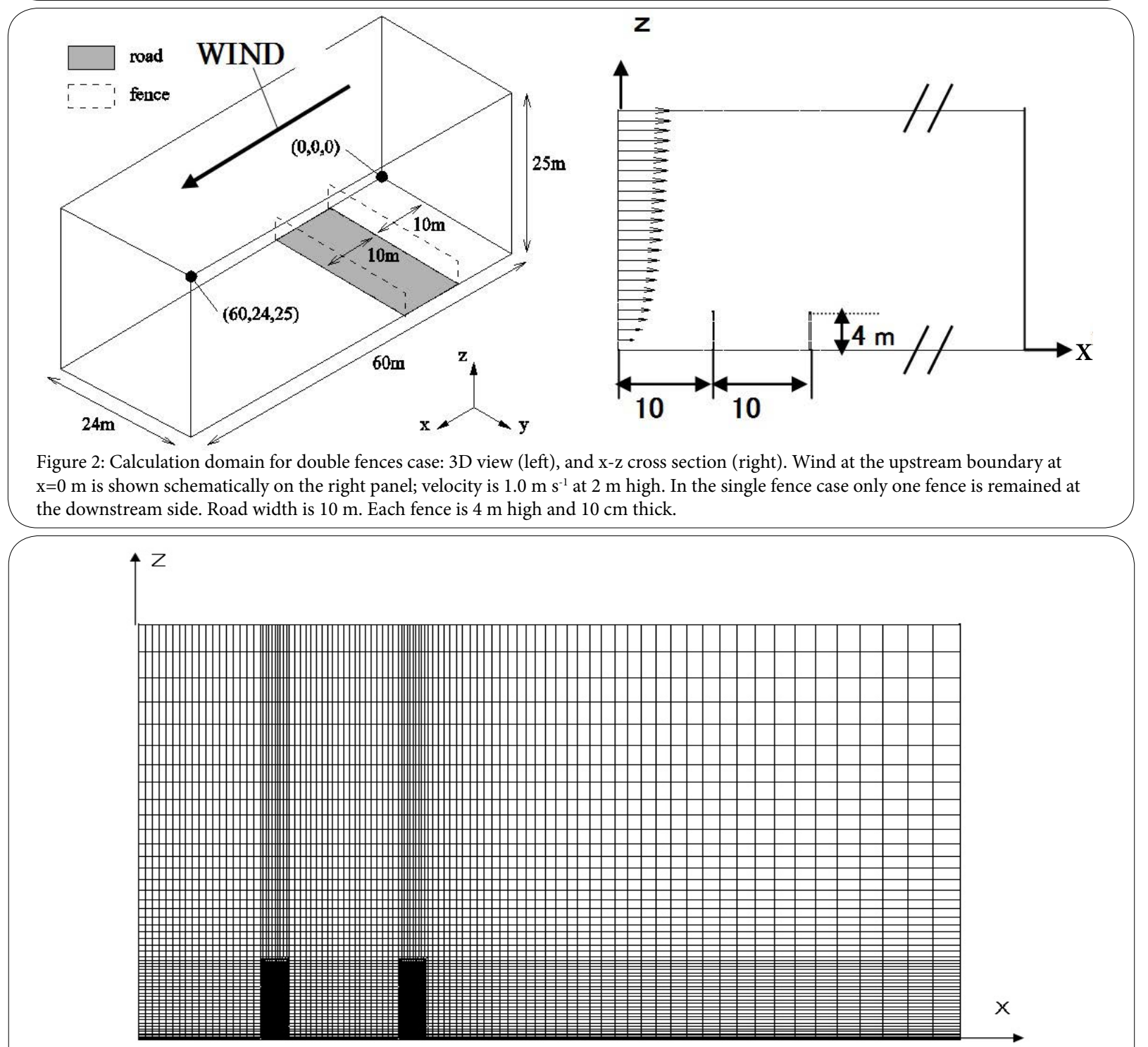

Figure 3: Grid system on $\mathrm{x}-\mathrm{z}$ plane.The fence of $10 \mathrm{~cm}$ thick is resolved with $2 \mathrm{~cm}$ grid for $\mathrm{x}$-direction, and its height of 4 $\mathrm{m}$ is expressed with $20 \mathrm{~cm}$ grid for $\mathrm{z}$ direction. 
Citation: Kitada T, Nagano M, Shimohara T, Yoshikawa M, Kanzaki T (2017) Numerical Study on Reduction of Ambient NOx Concentration by a Flow-through ACF (Activated Carbon Fibers) Fences. Int J Earth Environ Sci 2: 131. doi: https://doi.org/10.15344/2456-351X/2017/131

Page 4 of 9

gradually enlarged up to $1 \mathrm{~m}$. For $\mathrm{z}$ direction, the grid size was $20 \mathrm{~cm}$ from ground to the top of the fence, and then gradually increased up to $1 \mathrm{~m}$ long. For y direction, the grid size was set constant at $1 \mathrm{~m}$.

$U_{1}(z)=\frac{u_{*}}{\kappa} \ln \left(\frac{z}{z_{0}}\right)$

Where we assumed that the roughness length $\mathrm{z}_{\mathrm{o}}=0.23 \mathrm{~m}$, and $\mathrm{U}_{1}$ at $\mathrm{z}=10 \mathrm{~m}$ is $1.8 \mathrm{~ms}^{-1}$ with Karman constant $=0.4$; then the friction velocity $\mathrm{u}^{\star}=0.19 \mathrm{~ms}^{-1}$ is estimated; Eq. (14) gives, for example, $\mathrm{U}_{1}$ $=0.7,1,1.4 \mathrm{~ms}^{-1}$ at $\mathrm{z}=1,2,4 \mathrm{~m}$, respectively.

Since the whole calculation domain is submerged in the surface layer, we set minimum values for $\mathrm{k}$ and so that the lower bound for diffusivity is assured in the road space: that is, the lowest diffusivity is $0.04 \mathrm{~m}^{2} \mathrm{~s}^{-1}$ for outside of the fences, and is molecular diffusivity for inside of the fences. Actually, the minimum calculated diffusivity was about $8.4 \times 10^{-5} \mathrm{~m}^{2} \mathrm{~s}^{-1}$ at the inside of the ACF fences which is several times larger than the molecular diffusivity.

\section{Results and Discussion}

For both double- and single-fence cases, performance of the ACF fences in NOx concentration reduction at the roadside was numerically evaluated. Two parameters characterizing ACF fence, $k_{c}$ and $\vec{R}_{c}$ were varied based on the laboratory experiments described in the section 3 .

Small $\bar{R}_{c}$ value gives short contact time of polluted air with ACF in the fence, and may lead to less reduction of NOx concentration. On the other hand, large $\bar{R}_{c}$ value is expected to result in the larger contact time and, hence, to enhance decrease of NOx concentration. However, since this large $\bar{R}_{c}$ largely limits the air flow passing through the ACF fence, the flow field itself may be significantly modified and thus NOx concentration around the road and fences is possibly changed. This means that we can know how the $\bar{R}_{c}$ value affects NOx field by only performing numerical simulation of air flow and pollutant transport in this situation. The rate constant for NOx removal reaction by $\mathrm{ACF}, k_{c}$ is definitely another important parameter determining NOx concentration.

It should be noted that Eq. (4) for NOx transport and chemical removal is linear with respect to its concentration, $\mathrm{C}$, and thus calculated concentration linearly responds to given emission source strength; this means the results of NOx concentration fields and profiles appeared in the following sub-sections can be interpreted following to various emission source scenarios; for example, if emission source strength from road is half of the current calculation (see sub-section 4.1), predicted concentrations will be half of the values shown in this study.

\section{Calculated NOx field}

\section{(1) Double fences}

Figure 4 shows calculated NOx concentration field; the left column, Figure $4(\mathrm{a}, \mathrm{c}, \mathrm{e})$, is for the smaller resistance case ("slit" type fence module) with $\bar{R}_{C}\left(\equiv \gamma \rho R_{C}\right)=400$, while the right column, Figure $4(\mathrm{~b}$, $\mathrm{d}, \mathrm{f}$ ), is for the larger resistance case ("panel" type fence module) with $\bar{R}_{c}=3700$. For these two cases of $\bar{R}_{c} 400$ and 3700 , effect of the NOx removal reactivity (varied $k_{c}$ value) is further compared; Figure $4(\mathrm{a}, \mathrm{b})$ is for $\bar{R}_{c}$ (no-NOx removal activity), Figure $4(\mathrm{c}, \mathrm{d})$ for $k_{c}=1$, and Figure $4(\mathrm{e}, \mathrm{f})$ for $k_{c}=3$.
In the case of $k_{c}=0$ (no chemical removal of NOx), the concentration fieldsin downstream area where $\mathrm{x}>20 \mathrm{~m}$ show almost same pattern for $\bar{R}_{c}=400$ (Figure 4a) and 3700 (Figure 4b). However, close observation of calculated flow and concentrationin the road space indicates difference in NOx field between $\bar{R}_{c}=400$ and 3700. Figure $5(a, b)$ are the same as Figure 4(a,b) but the calculated NOx fields (with different contour scales) are magnified in the road space to see fine structures. Figure 5a with smaller $\bar{R}_{c}(=400)$ demonstrates that clean air at the outside of the roadtends to beintroduced into the road space through the upstream fence, and the clean air disturbs contact of the pollutant-rich air with the fence as marked with red circle in Figure 5 a. In contrast, Figure 5b of the larger $\bar{R}(=3700)$ shows the high NOx air keeps contact with the upstream fence. At a height of $2 \mathrm{~m}$ of the ACF fence on upstream side, calculated wind velocity is summarized as follows: $1 \mathrm{~ms}^{-1}$ at upstream boundary, the wind impinging onto the ACF fence surface was about $15 \mathrm{~cm} \mathrm{~s}^{-1}$, and the wind inside the ACF fence was about 4 and $1 \mathrm{~cm} \mathrm{~s}^{-1}$ for $\bar{R}_{c}=400$ and 3700 , respectively.

Differences between Figure 4(a,b) and Figure 4(c-f) show NOx removal effect by ACF fences. Though we discuss the NOx reduction quantitatively later in the subsection 5.3, large decrease in $\mathrm{NOx}$ concentration in the area downstream of the road $(x>20 \mathrm{~m})$ can be seen in Figure 4(c-f); moreover, the decrease is more eminent in the lower height near the ground surface; for example, at the ground level of $\mathrm{x}=40 \mathrm{~m}$, the NOx concentration at $170 \mathrm{ppb}$ with no-ACF effect (Figure $4 \mathrm{~b}$ ) decreases to $110 \mathrm{ppb}$ with $k_{c}=1$ (Figure $4 \mathrm{~d}$ ) and $95 \mathrm{ppb}$ with $k_{c}=3$ (Figure $4 \mathrm{f}$ ).

In the active ACF cases with 1 and 3 Figure $4(\mathrm{c}-\mathrm{f})$, NOx concentration in downstream area $(x>20 \mathrm{~m})$ is always higher in the lower resistance coefficient of $=400$ (Figs. $4 \mathrm{c}, \mathrm{e}$ ) than the $=3700$ case (Figure $4 \mathrm{~d}$ and Figure 4f). This difference indicates lowerNOx removal efficiency of the ACF fence with $=400$ in the road space; that is, as described above, contact of NOx-rich air with the ACF fence is suppressed by the clean air introduced from outside of the road (Figure 5a) because of lower resistance of the $=400 \mathrm{ACF}$ fence to the flow. Finally, it can be said that Figure 4 and Figure 5 show importance to utilize high concentration zone, formed by road structure such as fence, for effective removal of pollutants.

\section{(2) Single fence}

Figure 6 shows calculated NOx fields of the single fence case. The largest difference found in Figure 6(c-f) (single fence) and Figure 4 (c-f) (double fences) is that in contrast to the double-fence case, in the single fence case the smaller $\bar{R}_{c}$ cases show better performance in reduction of NOx concentration; see difference between Figure 6(c,e) with $\bar{R}_{c}=400$ and Figure $6(\mathrm{~d}, \mathrm{f})$ with $=3700$. To see reason of this better performance, Figure $7(\mathrm{a}, \mathrm{b})$ present the flow and NOx fields magnified in the area around the road space; they are the same as Figure 6(a, b) but with different contour scale. By comparing Figure 7 a of the $\bar{R}$ $=400$ fence with Figure $7 \mathrm{~b}$ of the $\bar{R}_{c}=3700$ fence, we can see larger pollutant mass flux through the fence in Figure $7 \mathrm{a}$ (see below the fence height of the area encircled with red line); hence, larger removal rate of NOx is expected for smaller resistance $\left(\bar{R}_{c}=400\right)$ fence when the fence has chemically active nature of ACF, as demonstrated in the comparison between Figure 6(c,e) and Figure 6(d, f).

Another observation is that Figure 6 for the single fence cases shows lower NOx concentration in the downstream area than Figure 4 for the double-fence cases. This can be attributed to the flow characteristic that in the single fence cases, circulating flow is not formed in the road 
Citation: Kitada T, Nagano M, Shimohara T, Yoshikawa M, Kanzaki T (2017) Numerical Study on Reduction of Ambient NOx Concentration by a Flow-through ACF (Activated Carbon Fibers) Fences. Int J Earth Environ Sci 2: 131. doi: https://doi.org/10.15344/2456-351X/2017/131

(a) $\mathrm{k}_{\mathrm{C}}=0, \bar{R}_{c}=400$

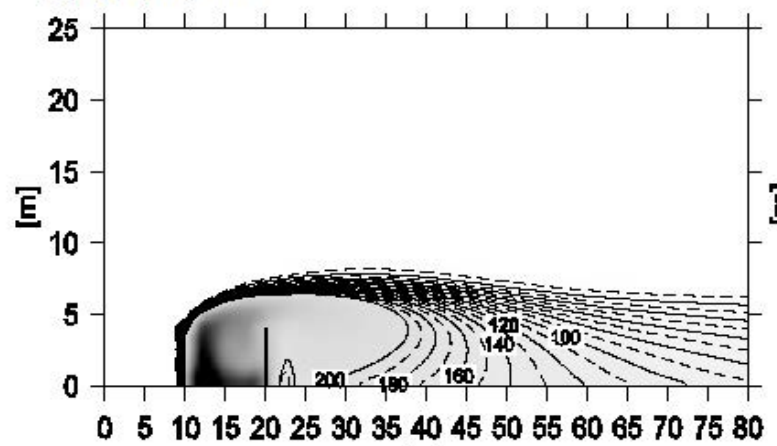

[m]

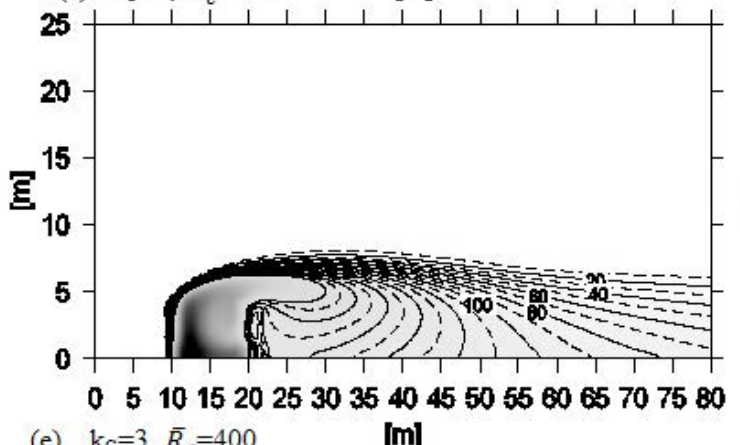

(b) $\mathrm{k}_{\mathrm{c}}=0, \bar{R}_{c}=3700$

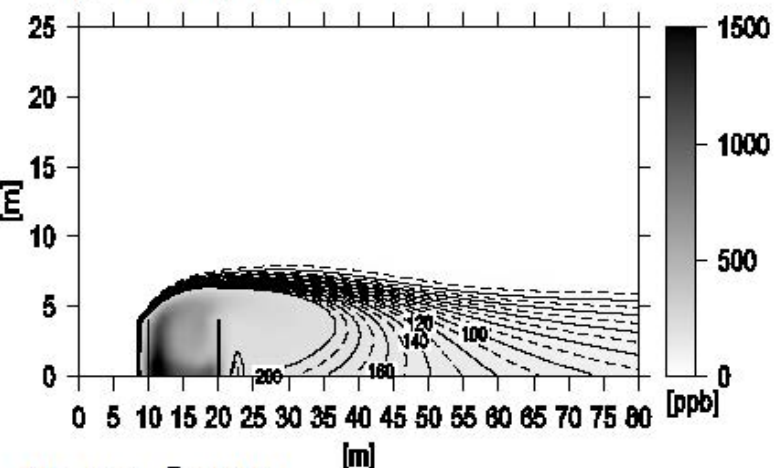

(d) $\mathrm{k}_{\mathrm{c}}=1, \bar{R}_{c}=3700$

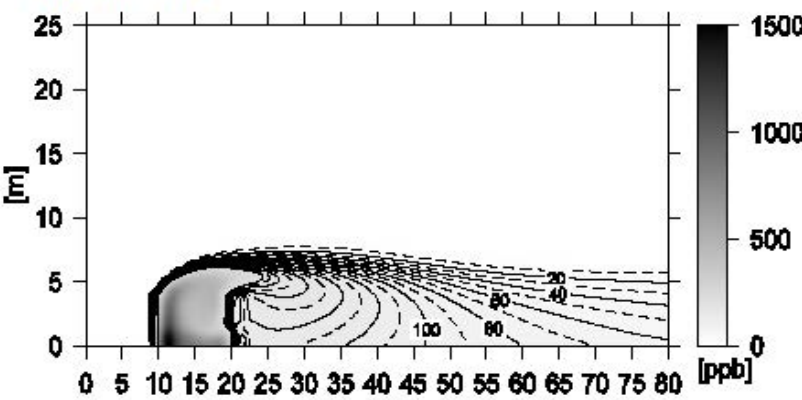

(f) $\mathrm{k}_{\mathrm{C}}=3, \bar{R}_{c}=3700$
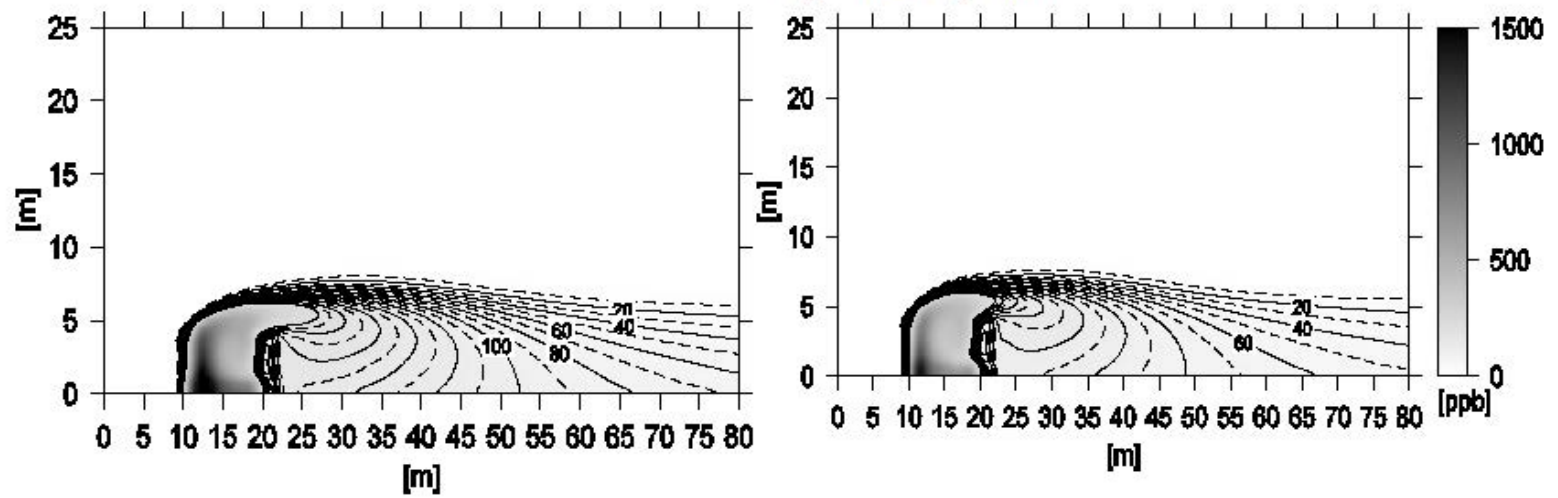

Figure 4: Vertical cross section, on $\mathrm{x}-\mathrm{z}$ plane, of calculated NOx at $\mathrm{y}=12 \mathrm{~m}$ (see Figure 2) in double-fence cases with $(\bar{R}=\gamma \rho R)$ and as parameters: (a, b) for no removal activity of ACF fences. (b, d) for removal activity with $k_{c}=1 \mathrm{~s}^{-1}$, and $(\mathrm{e}, \mathrm{f})$ for removal activity with $k_{c}=3 \mathrm{~s}^{-1}$. Contour interval is $10 \mathrm{ppb}$.
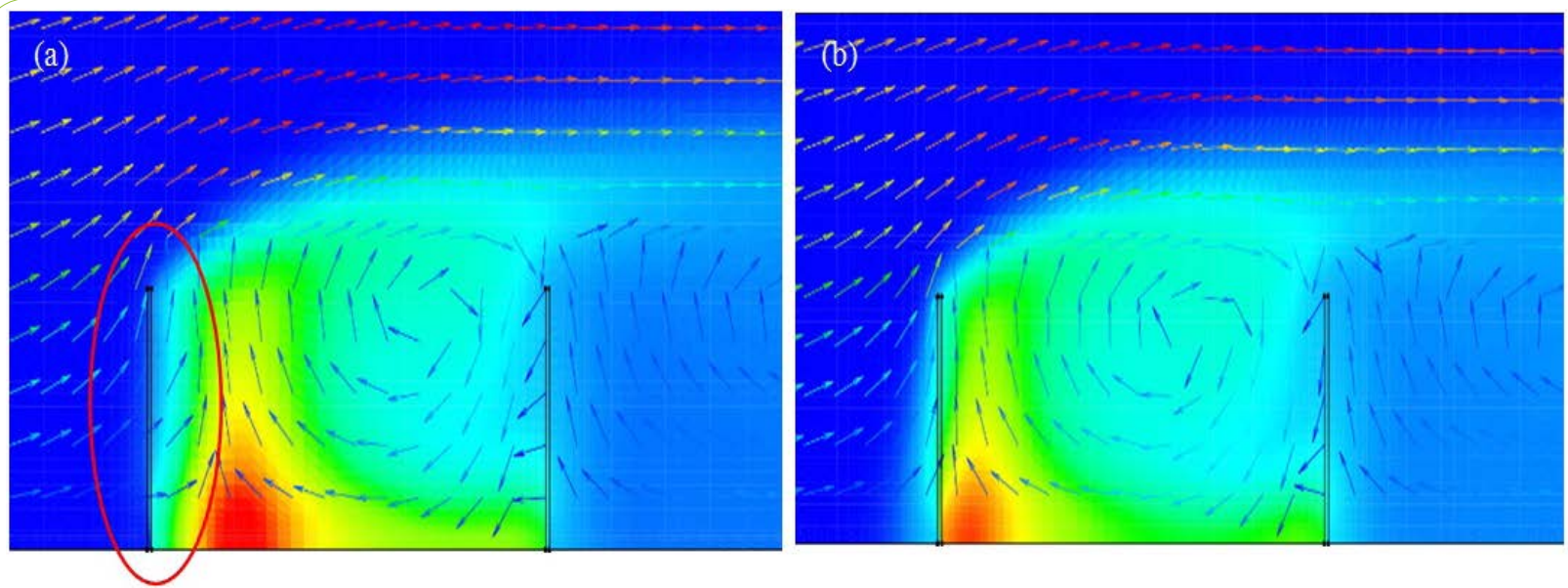

Figure 5: Double-fence: close look of flow and NOx fields in- and around- the road space: (a) $k=0, \bar{R}=400$ (same as Figure 4a but with different contour scale), and (b) $k_{c}=0, \bar{R}_{c}=3700$ (same as Figure $4 \mathrm{~b}$ but with different contour scale) 
Citation: Kitada T, Nagano M, Shimohara T, Yoshikawa M, Kanzaki T (2017) Numerical Study on Reduction of Ambient NOx Concentration by a Flow-through ACF (Activated Carbon Fibers) Fences. Int J Earth Environ Sci 2: 131. doi: https://doi.org/10.15344/2456-351X/2017/131
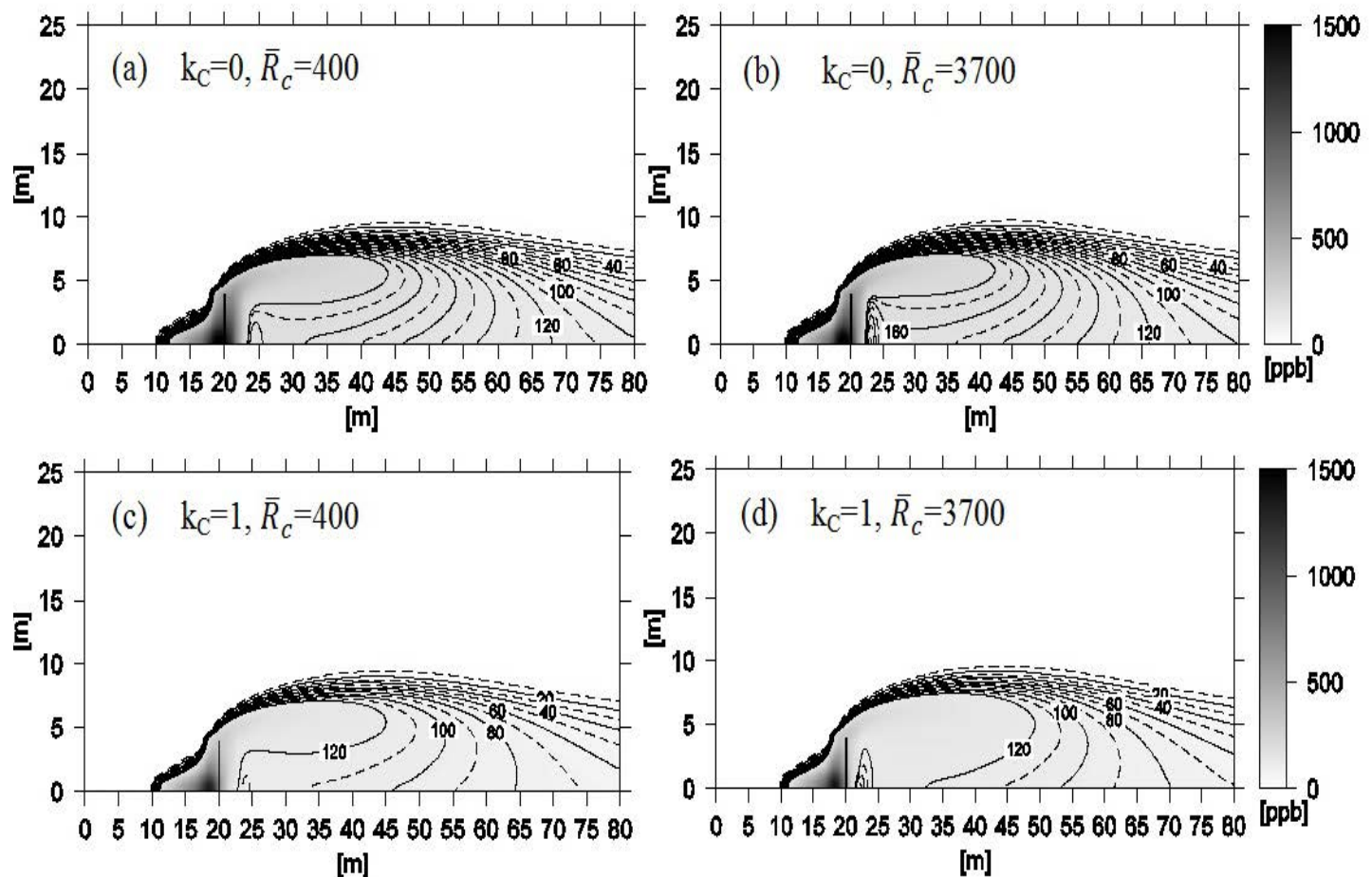

(e) $\mathrm{k}_{\mathrm{C}}=3, \gamma \rho \mathrm{Rc}=400$

(f) $\mathrm{k}_{\mathrm{C}}=3, \gamma \rho \mathrm{Rc}=3700$
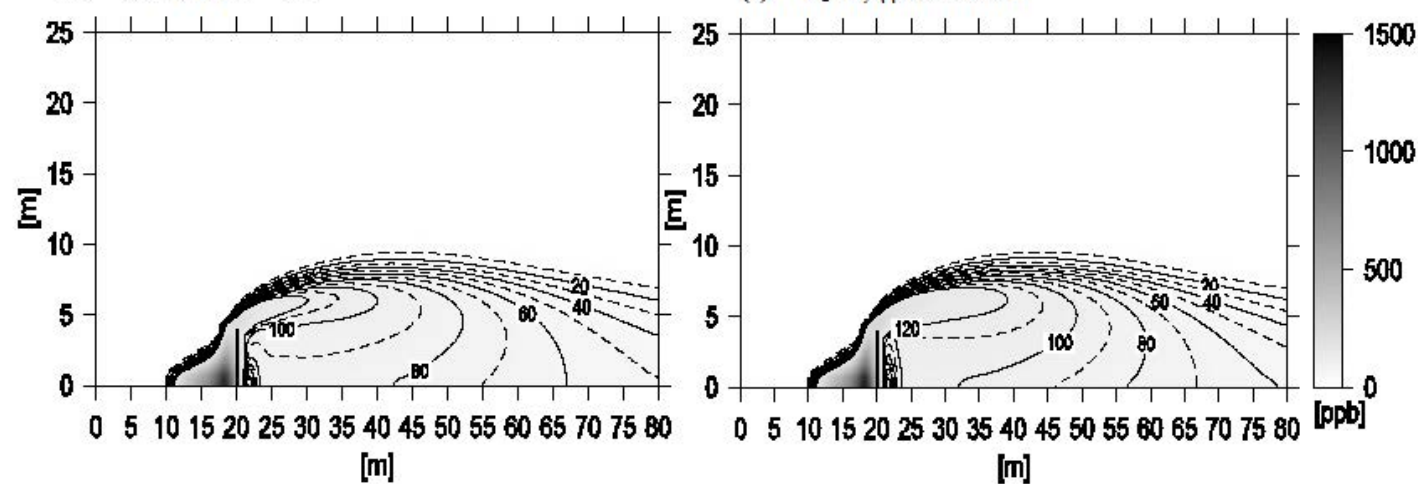

Figure 6: Same as in Figure 4 but for "single fence": (a, b) for no removal activity of ACF fences. (c, d) for removal activity with $k_{c}=$ $1 \mathrm{~s}^{-1}$, and $(\mathrm{e}, \mathrm{f})$ for $k_{c}=3 \mathrm{~s}^{-1}$. Contour interval is $10 \mathrm{ppb}$.
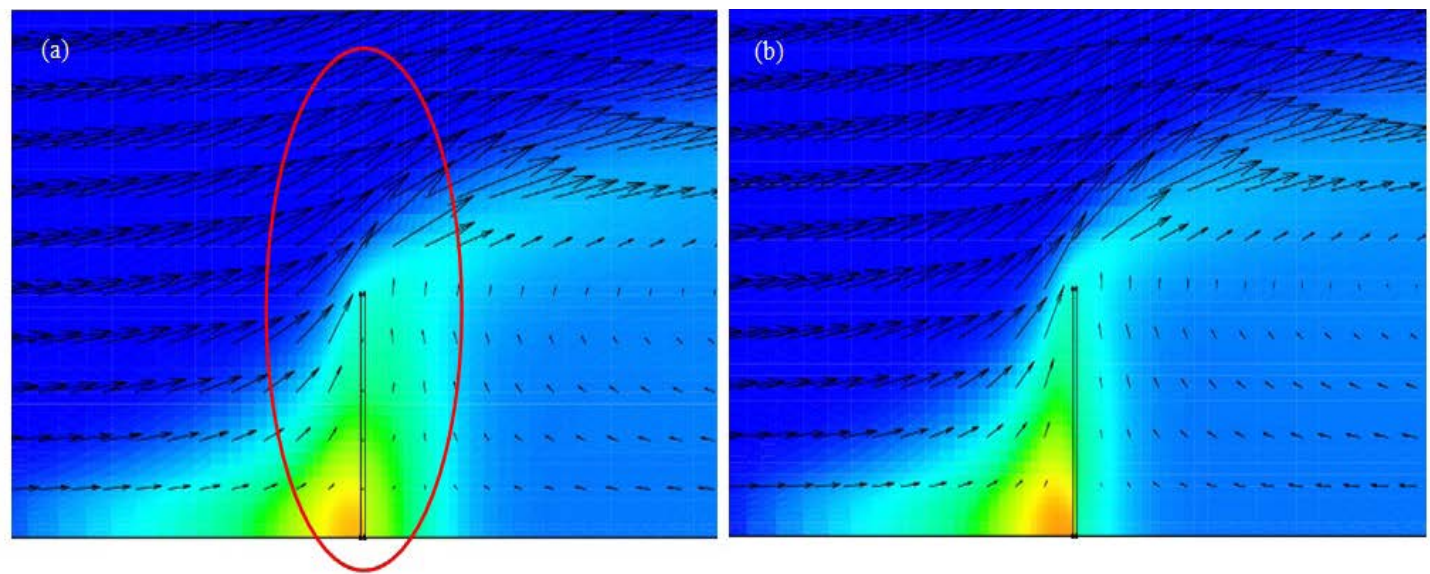

Figure 7: Single-fence: close look of flow and NOx fields in- and around- the road space: (a) $k_{c}=0, \bar{R}=400$ (same as Figure $6 a$ but with different contour scale), nd (b) $k_{c}=0, \bar{R}_{c}=3700$ (same as Figure $6 \mathrm{~b}$ but with different contour scale) 


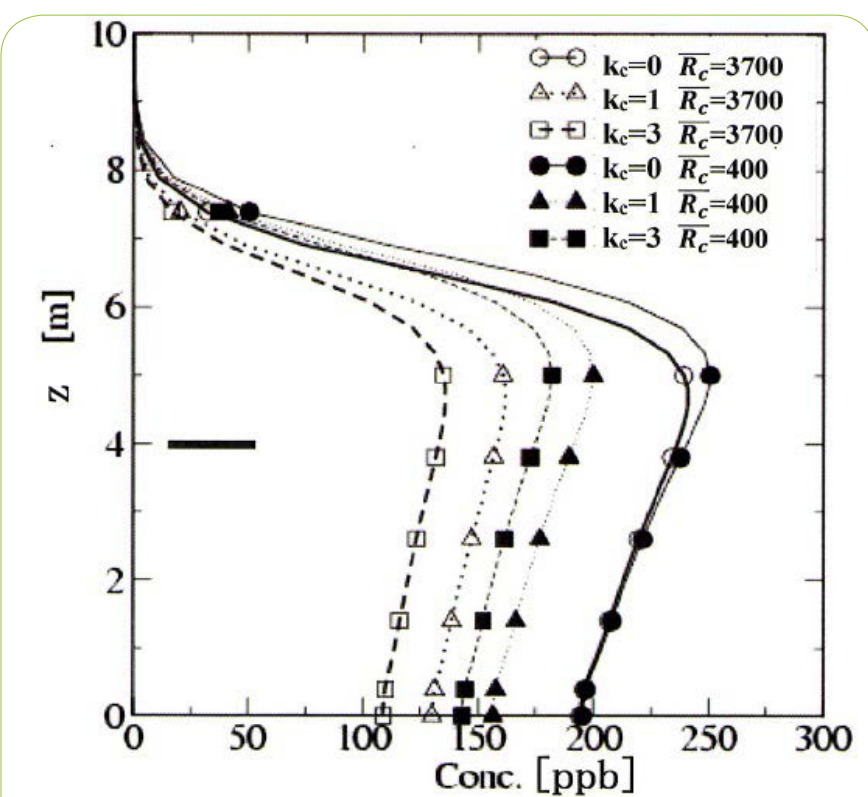

Figure 8: Double-fence: vertical profiles of NOx (ppb) at $10 \mathrm{~m}$ downstream from lee-ward fence. Profiles are shown with the parameter-values of $\overline{\mathrm{R}}_{c}$ and $\mathrm{K}_{\mathrm{c}}$ (see the subsection 3 for detail). Solid lines with open and solid circles indicate no-removal reaction cases $\left(\mathrm{K}_{c}=0 \mathrm{~s}^{-1}\right)$. The symbol " - " shows fence height

space and thus large upward flow is generated over the single fence placed on the downwind side of the road as shown in Figure 7; in this situation, polluted air mass in the road space tends to be higher lifted over the ACF fence, leading lower NOx concentration in the downstream area, in particular, at lower heights near the ground as shown in Figure 6.

\section{Evaluation of NOx concentration reduction by ACF fence}

Figure 8 and 9 show vertical profiles of calculated NOx at $10 \mathrm{~m}$ downwind from the leeward side fence (namely, at $\mathrm{x}=30 \mathrm{~m}$ and $\mathrm{y}=$ $12 \mathrm{~m}$ in Figure 2) for the double- and single-fence case, respectively.

Figure 8 ("double-fence" case) demonstrates that ACF fences can reduce near-surface NOx concentration at the roadside by $15 \sim 40 \%$ than the no-removal activity fence $\left(k_{c}=0\right.$; open and solid circles in Figure 8). Since difference in NOx concentration between cases with $k_{c}=1$ (symbol "triangle") and 3 (symbol "square") is relatively small, NOx removal process by ACF is thought to be rather diffusionlimited if $k_{c}$ value exceeds around $1 \mathrm{~s}^{-1}$. Moreover, it is suggested that fence of larger resistance, which corresponds to "panel" type module with $\bar{R}_{c}=3700$, can lead to larger decrease of NOx concentration (open symbols in Figure 8) than that of lower resistance (solid symbols in Figure 8) with "slit" type module of $\bar{R}_{c}=400$. Again this may be explained that the low resistance fence on upwind side allows clean air outside the road to intrude into the road space and the clean air prevents polluted air in the road space to contact with the ACF fence on the upwind side.

Also in single-fence situation, it is shown that the ACF fences can cut NOx concentration by $30 \sim 55 \%$ (Figure 9). In contrast to the double-fence case, that fence with small resistance $\left(\bar{R}_{c}=400\right)$ is better for lowering NOx concentration is indicated. In the case of single fence placed on the leeside of the road, the lower resistance fence leads to higher pollutant flux into the ACF layer Figure $7(a, b)$, and thus larger reduction of NOx can be expected.

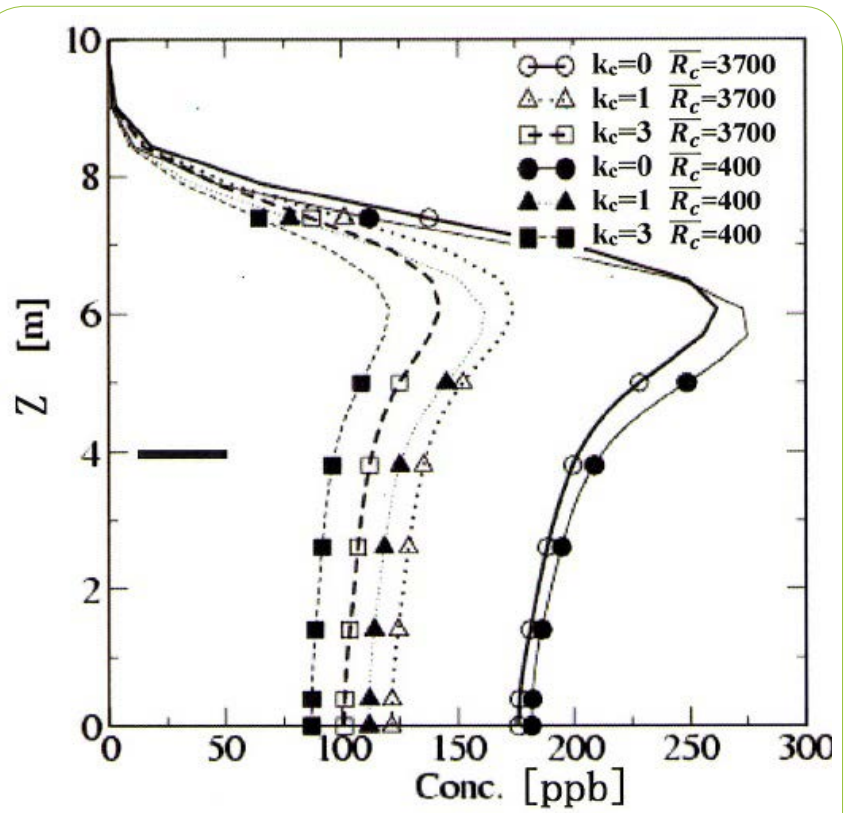

Figure 9: Same as Figure 8 but for single fence cases.

Moreover, it is shown that the single-fence case (Figure 9) gives rather smaller NOx concentration at lower heights, for example, below $4 \mathrm{~m}$ than the double-fence case (Figure 8 ). This is again attributable to the enhanced upward motion over the leeward fence in single fence cases (Figure 7) compared with double-fence cases (Figure 5), leading to higher vertical transport of the pollutant and hence lower concentration near the ground surface in the leeward space of the road.

\section{Summary and Conclusions}

In this study, a new method to reduce ambient NOx concentration without excess energy use was proposed and its performance was numerically evaluated. The method is to set a "porous" flow-through fence filled inside with ACF (Activated Carbon Fibers) along heavy traffic road. ACF is pre-treated carbon fiber [16] and highly effective in removal of $\mathrm{NOx}, \mathrm{SO}_{2}$, etc. By using a control volume method, partial differential equations of flow, turbulence, and NOx transport were simultaneously solved to predict NOx concentration reduced by the double- and single-ACF-fence.

Two important parameters on the ACF fence were identified: one is the resistance of ACF layer to the air flow, the resistance coefficient $\bar{R}$, and the other is the removal reactivity of ACF for NOx, the reaction coefficient $k_{c}$. With these two parameters varied, performance in pollutants' removal of both double-fences placed on the both sides of the road and single fence set on the lee side of the road was investigated. It should be noted that Eq. (4) for transport and chemical removal of NOx is linear with respect to its concentration $\mathrm{C}$ and the calculated concentration $\mathrm{C}$ linearly responds to the value of emission strength; therefore the calculated concentration fields and profiles in this study can be readily used to estimate those inother situation under arbitrarily specified new emission strength just by comparingthe new emission with that used in this study (described in subsection 4.1) Obtained results showed: 
Citation: Kitada T, Nagano M, Shimohara T, Yoshikawa M, Kanzaki T (2017) Numerical Study on Reduction of Ambient NOx Concentration by a Flow-through ACF (Activated Carbon Fibers) Fences. Int J Earth Environ Sci 2: 131. doi: https://doi.org/10.15344/2456-351X/2017/131

Page 8 of 9

(1) in the double-fence case, high concentration zone is formed near the ACF fence on upstream side due to the circulation generated in the road space. In this case, the fence with higher ventilation (low $\bar{R}_{c}$ value) placed on the upstream side does not have efficient contact with the polluted air in the road space because clean air coming into the road space through the ACF fence prevents it (Figure 5). Thus, in the double-fence case, ACF fence with higher $\bar{R}$ value tends to give better results (Figure 4 and Figure 8 ). For example, even relatively low chemical reactivity fence with $k=1 \mathrm{~s}^{-1}$ can decrease surface NOx concentration by about 35\% (see Figure 8). In total, it is indicated that ACF fences (with $k_{c}=1,3 \mathrm{~s}^{-1}$ ) can reduce NOx concentration, in the lower layer below the height of $4 \mathrm{~m}$ at $10 \mathrm{~m}$ downwind from the roadside, by $15 \sim 50 \%$ than the no-removal activity fence $\left(k_{c}=0\right)$.

(2) in the single fence case, on the other hand, smaller resistance of the ACF fence is better for the pollutants' removal, since higher pollutants flux through the ACF layer is expected with the ACF fence of low $\bar{R}$ value (Figure 7). In total, in single-fence situation, it is shown that the ACF fences can cut NOx concentration by $30 \sim 55 \%$ (Figure 6 and 9).

(3) in both double- and single- fence cases, the process decreasing NOx concentration is suggested rather diffusion-limited if $k_{c}$ is larger than about $1 \mathrm{~s}^{-1}$, indicating frequency of the contact of polluted air with the fences is important.

\section{Nomenclature}

$\mathrm{B}_{\mathrm{i}}=$ resistance to air flow in i direction by ACF layer defined in Eq. (3), (L T-2)

$\mathrm{C}=$ dimensionless concentration of NOx in air in Eq. (4)

$\mathrm{C}_{1}, \mathrm{C}_{2}, \mathrm{C}_{\mu}=$ parameters in the standard $\mathrm{k}$ - $\varepsilon$ model; the values are listed in Eq. (9)

$\mathrm{K}_{\mathrm{ij}}, \mathrm{K}_{\mathrm{j} \mathrm{k}}=$ area-porosity tensor of ACF layer in Eq. (1), (2), (4), (5), and (6); unit tensor is assumed; for example, $K_{i j}=1$ for $i=j$, and 0 for $i \neq j$.

$\mathrm{k}=$ turbulent kinetic energy in Eq. (5), (6), and (8), ( $\left.\mathrm{L}^{2} \mathrm{~T}^{-2}\right)$

$\mathrm{k}_{\mathrm{c}}=$ removal rate coefficient of NOx by ACF layer in Eq. (4), (10), and (11), $\mathrm{T}^{-1}$

$\mathrm{L}=$ thickness of ACF layer in Eq. (12) and (13), L

$[\mathrm{NOx}]=$ dimensionless concentration of NOx in air in Eq. (10)

$\left[\mathrm{NO}_{\mathrm{x}}\right]_{\mathrm{i}}=$ dimensionless concentration of NOx in air at inlet in Eq. (11)

$\left[\mathrm{NO}_{\mathrm{x}}\right]_{\mathrm{o}}=$ dimensionless concentration of NOx in air at outlet in Eq. (11)

$\mathrm{P}=$ shear production term of turbulent kinetic energy in Eq. (5), (6), and (7), $\left(\mathrm{L}^{2} \mathrm{~T}^{-3}\right)$

$\mathrm{p}=$ pressure of air in Eq. (2), $\left(\mathrm{N} \mathrm{L}^{-2}\right)$

$\mathrm{p}_{1}, \mathrm{p}_{2}=$ pressure of air in Eq. (12) and (13), $\left(\mathrm{N} \mathrm{L}^{-2}\right)$

$\mathrm{R}_{\mathrm{c}}=$ resistance coefficient in Eq. (3), $\mathrm{T}^{-1}$

$\bar{R}_{c}\left(=\gamma \rho R_{c}\right)=$ modified resistance coefficient in Figure 4 through 9, $\left(\mathrm{M} \mathrm{L}^{-3} \mathrm{~T}^{-1}\right)$

$\mathrm{t}=$ time, $\mathrm{T}$

$\mathrm{U}_{\mathrm{i}}=$ air flow velocity for i direction in Eq. (1), (2), (4), (5), (6), and (7);

$\mathrm{i}=1,2,3$ for $\mathrm{x}, \mathrm{y}, \mathrm{z}$ direction, respectively, $\left(\mathrm{L} \mathrm{T}^{-1}\right)$

$\mathrm{u}_{*}=$ friction velocity in Eq. (14), $\left(\mathrm{L} \mathrm{T}^{-1}\right)$

$\mathrm{V}=$ air flow velocity in Eq. (12) and (13), $\left(\mathrm{L} \mathrm{T}^{-1}\right)$

$\mathrm{x}_{\mathrm{i}}$ = coordinate axis; $\mathrm{i}=1,2,3$ for $\mathrm{x}, \mathrm{y}, \mathrm{z}$ direction, respectively; for example, $\mathrm{x}_{3}(=\mathrm{z})$ for vertical direction and positive for upward, $\mathrm{L}$ $\mathrm{z}=$ vertical coordinate axis $\left(=\mathrm{x}_{3}\right)$ in Eq. (14); height above ground surface, $\mathrm{L}$

$\mathrm{z}_{0}=$ roughness length in Eq. (14), L

\section{Greek Letters}

$\alpha=$ coefficient in Eq. (12) and (13). $\beta=$ coefficient in Eq. (12).

$\Gamma_{\mathrm{t}}=$ turbulent diffusivity of pollutant in air in Eq. (4) assumed equal to $v_{\mathrm{t}}$ as in Eq. (8), $\left(\mathrm{L}^{2} \mathrm{~T}^{-1}\right)$

$\gamma=$ volume porosity of ACF layer as assumed porous media in Eq. (3), (4), (5), (6), and (13).

$\varepsilon=$ dissipation rate of turbulent kinetic energy in Eq. (5), (6), and (8), $\left(\mathrm{L}^{2} \mathrm{~T}^{-3}\right)$

$\kappa=$ Karman constant in Eq. (14)

$v=$ molecular kinematic viscosity of air in Eq. (12) and (13), $\left(\mathrm{L}^{2} \mathrm{~T}^{-1}\right)$

$v_{t}=$ turbulent kinematic viscosity of air evaluated by Eq. (8), $\left(\mathrm{L}^{2} \mathrm{~T}^{-1}\right)$

$\rho=$ air density in Eq. (2), (4), (12), and (13), $\left(\mathrm{M} \mathrm{L}^{-3}\right) \sigma_{k}, \sigma_{\varepsilon}=$ parameters in the standard k- $\varepsilon$ model; the values are listed in Eq. (9)

\section{Competing Interests}

The authors declare that they have no competing interests.

\section{Funding}

This work was supported by Grant for Research and Development in Construction Technology, Grant No. 5102, Ministry of Land, Infrastructure and Transport, Japan, and in part by JSPS-MOE Core University Program on Urban Environment.

\section{References}

1. Aichi Prefectural Government/Dept. Environment, Japan (2015) Report on Air Pollution Survey for FY2014 (Heisei 26-Nendo TaikiOsenChousaHoukoku), Vol. 53, 244 pages (in Japanese).

2. Aichi Prefectural Government/Dept. Construction, Japan (2008) Report on Air-purifying Experiments Using Soil Layers on the Road Traversing Chita Peninsula (Chita Ohdan Road), 300pages (in Japanese).

3. Mochida I, Kisamori S, Hironaka M, Kawano S, Matsuura Y (1994) Oxidation of NO into NO2 over activated carbon fibers. Energy Fuels 8: 1341-1344.

4. Yoshikawa M, Yasutake A, Mochida I (1998) Low-temperature selective catalytic reduction of NOx by metal oxides supported on active carbon fibers. Applied Catalysis A: General 173: 239-245.

5. Shirahama N, Mochida I, Korai Y, Choi KH, Enjoji T, et al. (2004) Reaction of $\mathrm{NO}_{2}$ in air at room temperature with urea supported on pitch based activated carbon fiber. Applied Catalysis B: Environment 52: 173-179.

6. Shimohara T, Niiya S, Mitoma S, Yoshikawa M, Kitada T (2011) Air purification technology using activated carbon fiber. I. NOx purification properties and the air purification technique by forced ventilation system with ACF. Journal Japan Society for Atmospheric Environment (TaikiKankyouGakkaishi) 46: 187-195.

7. Shimohara T, Niiya S, Mitoma S, Yoshikawa M, Kitada T (2012) Air purification technology using activated carbon fiber. II. Study on de-NOx system using ACF through the natural ventilation system. Journal Japan Society for Atmospheric Environment(Taki-KankyouGkkaishi) 47: 58-66.

8. Launder BE, Spalding DB (1974) Numerical computation of turbulent flows. Computer Methods in Applied Mechanics and Engineering 3: 269-289.

9. Rodi W (1984) Turbulent Models and Their Application in Hydraulics: A State of the Art Review, 2nd edition. IAHR, 104 pages.

10. Nagano M, Kitada T, Shimohara T, Kanzaki T, Ichikawa Y, et al. (2008) ACF (Activated Carbon Fiber) for reduction of ambient NO2 concentration at the roadside. Advances in Wind and Structures (AWAS'08), 1203-1212. 
Citation: Kitada T, Nagano M, Shimohara T, Yoshikawa M, Kanzaki T (2017) Numerical Study on Reduction of Ambient NOx Concentration by a Flow-through ACF (Activated Carbon Fibers) Fences. Int J Earth Environ Sci 2: 131. doi: https://doi.org/10.15344/2456-351X/2017/131

11. Nagano M, Kitada T, Kanzaki T, Ichikawa Y, Shimohara T, et al. (2009) Reduction of ambient NOx concentration at roadside by the porous fences filled with ACF: comparison of numerical model with wind tunnel experiment Global Environmental Research (ChikyuKankyouKenkyuRonbunshu), Japan Society of Civil Engineers 17: 115-121.

12. Kitada T, Kurodai Y, Shimohara T, Kanzaki T, Yoshikawa M (2014) Numerical study on reduction of ambient NOx, PM, and VOCs concentrations by ACF (Activated Carbon Fiber) fences: effects of generated air flow and chemical reactivity of the ACF fences. Air Pollution Modeling and its Application XXII, Springer 159-165.

13. ANSYS, 2005: ANSYS CFX-Solver Manuals.

14. Perry RH, Chilton CH (1973) Chemical Engineers' Handbook, 5th edition, p. 5-54, McGraw-Hill.

15. Tokairin $\mathrm{T}$, Kitada $\mathrm{T}$ (2005) Study on the effect of porous fence on air quality and traffic noise level around a double-decked road structure. Environ Monit Assess 105: 121-143.

16. Yoshikawa M, Shimohara T, Kitada T (2007) Development of prevention technology of air pollution by Activated Carbon Fiber. Proceedings of 13th Seminar of JSPS-MOE Core University Program on Urban Environment October 3-4, Tsinghua University, Beijing, China, 117-122. 